ORIGINAL ARTICLE

\title{
Personality traits in musicians
}

\author{
Nikita Gjermunds ${ }^{1 \cdot A, B, E, F}$, Inge Brechan ${ }^{2 \cdot A, B, E, F}$, Svein Åge K. Fohnsen ${ }^{2 \cdot C, D, E}$, \\ Reidulf $G$. Watten (D) $^{2 \cdot C, D, E, F}$ \\ 1: Child and Adolescent Psychiatric Outpatient Treatment, Department Kongsvinger, Akershus University Hospitality \\ Trust, Norway \\ 2: Department of Psychology, Inland Norway University of Applied Sciences - INN University, Norway
}

\section{BACKGROUND}

Performing music is a complex creative activity which in addition to professional skills requires phantasy, a sense of aesthetics, cognitive involvement, intellectual curiosity, perceptual sensitivity, mental flexibility, but also discipline, motor precision and speed, attention endurance, emotional expression and communication. Many of these characteristics are also reflected in personality traits such as Openness, Extraversion, Conscientiousness and to some degree Neuroticism. Previous research has investigated the differences between personality traits amongst musicians, but there are few studies that compare personality characteristics between musicians and non-musicians.

\section{PARTICIPANTS AND PROCEDURE}

Using the Ten-Item Personality Measure (TIPI) the present study investigated Big Five personality traits in a sample of musicians $(n=509)$ compared to non-musicians $(n=201)$.

\section{RESULTS}

Controlled for gender and age, the findings demonstrated that musicians had significantly higher scores on Open- ness and lower scores on Conscientiousness compared with non-musicians. There were no significant differences between the groups in Extraversion, Agreeableness and Emotional Stability-Neuroticism. The differences were larger for Openness than for Conscientiousness.

\section{CONCLUSIONS}

Musicians seem to differ from non-musicians in two traits: somewhat lower scores on Conscientiousness, and considerably higher scores in Openness to experience. Thus, Openness seems to be the most typical personality trait for musicians. There were no significant differences in Extraversion, Agreeableness or Emotional Stability (Neuroticism) between the two groups. These results suggest that musicians are more creative and openminded than nonmusicians.

\section{KEY WORDS}

musicians; non-musicians; personality traits; openness

Corresponding author - Reidulf G. Watten, Department of Psychology, Inland Norway University of Applied Sciences

- INN University, P.O. Box 400, 2418 Elverum, Norway, e-mail: reidulf.g.watten@inn.no

AUthors' CONTRIBUtion - A: Study design - B: Data collection - C: Statistical analysis - D: Data interpretation .

E: Manuscript preparation · F: Literature search · G: Funds collection

to CITE this ARTICLE - Gjermunds, N., Brechan, I., Johnsen, S. A. K., \& Watten, R. G. (2020). Personality traits in musicians.

Current Issues in Personality Psychology, 8(2), 100-107.

RECEIVED 24.04.2020 • REVIEWED 27.05.2020 • ACCEPTED 16.06.2020 • PUBLISHED 30.06.2020 


\section{BACKGROUND}

Performing music is a complex creative activity which in addition to professional skills requires phantasy, sense of aesthetics, cognitive involvement, intellectual curiosity, perceptual sensitivity, mental flexibility, but also discipline, motor precision and speed, attention endurance, emotional expression and communication (Juslin, 2003; Palmer, 1997). Many of these characteristics are also reflected in personality traits such as Openness, Extraversion, Conscientiousness and to some degree Neuroticism (Zhao \& Seibert, 2006). Musicians could, therefore, have trait similarities. Some researchers have addressed this issue. For example, in a seminal study, Kemp (1996) identified common personality traits such as introversion, sensitivity, independence and anxiety. His findings were partly supported by Shuter-Dyson (2000), who found that male and female music students scored higher on Extraversion than male and female non-musicians and that female music students were more neurotic and tender-minded than female non-musicians. A high degree of perfectionism and intrinsic motivation also seem to be associated with musicians, factors reflecting Conscientiousness (Smith et al., 2018). However, there are mixed findings on this trait in the literature. Stoeber and Eismann (2007) found elevated scores among young musicians, whereas Yöndem, Yöndem, and Per (2017) founder lower scores. Also Vaag, Sund, and Bjerkeset (2018), comparing musicians to a representative sample of the general workforce, reported lower levels of Conscientiousness but higher levels of Neuroticism and Openness. They found no significant differences in Extraversion and Agreeableness.

Personality traits are both positively (e.g. Extraversion) and negatively (e.g. Neuroticism) related to mental health and treatment (Bucher, Suzuki, \& Samuel, 2019) and clinical studies on musicians are therefore interesting. For instance, performance anxiety and distress have been identified among professional and advanced musicians across a variety of musical genres such as classical, jazz and popular music (Papageorgi, Creech, \& Welch, 2013). Also Vaag, Bjørngaard, and Bjerkeset (2016) showed that symptoms of anxiety and depression were highly prevalent among professional musicians. Personality-related coping styles could be one factor behind reports of these mental health problems (Panayiotou, Kokkinos, \& Kapsou, 2014), a point of view also corroborated by a recent study showing the impact of Neuroticism on the use of medication and mental health care among musicians (Langvik, Bjerkeset, \& Vaag, 2019). Apparently, further studies describing the role of emotional stability and Neuroticism in musicians should be undertaken.

Openness is particularly interesting since this trait is associated with cognitive engagement, explo- ration (Kaufman et al., 2016) and creativity (George \& Zhou, 2001; Karwowski \& Lebuda, 2016; Puryear, Kettler, \& Rinn, 2017). Creative activities will activate emotional-cognitive processes and engage the human brain in several ways. For instance, it has been demonstrated that the prefrontal cortex (PFC), which is involved several high-order executive cognitive functions, is also involved in divergent thinking, a crucial part of creativity (Heilman, Nadeau, \& Beversdorf, 2003). In addition, when performing music, various regions of the parietal and temporal lobes are bilaterally activated, and these regions have reciprocal connections with the frontal lobes. This implies that processed sensory information of various modalities (i.e. visual, auditory and proprioceptive information) can be integrated with ongoing creative processes (López-González \& Limb, 2012). Openness also seems to be specifically associated with vivid dreaming and dream recall (Watson, 2003) in addition to mental absorption and hypnotizability (Glisky \& Kihlstrom, 1993), both revealing the ability to be emotionally and cognitively involved in aesthetic experiences and activities. Moreover, individuals scoring high on Openness have been found to demonstrate acceptance, curiosity, and tolerance for new ideas, and they also seem to have a need for intellectual and emotional stimulation (McCrae \& Costa, 1997), and a broad spectrum of interests (McCrae \& Costa, 2008). They may also be more likely to listen to complex music (such as classical music) and report listening to music for intellectual reasons, while people with a higher score on Neuroticism may listen to music to regulate their emotions (ChamorroPremuzic \& Furnham, 2007). Elevated scores on Openness could, therefore, be an advantage for musiciansAs summarized, there are rather few comprehensive controlled studies exploring personality traits in musicians. The majority of the investigations seem to consist of studies on rather small samples of professional musicians or music students in various musical genres or instrument groups (e.g. Butkovic \& Modrusan, 2019). The research designs and methodological approaches are also quite different and a variety of personality tests has been used: the $16 \mathrm{PF}$ (Buttsworth \& Smith, 1995), EPQ-R (Shuter-Dyson, 2000), Myers-Briggs (MacLellan, 2011), BFI-20 (Vaag et al., 2018), and IPIP-50 (Butkovic \& Rancic Dopudj, 2017). In addition, the studies also have quite different comparison groups both in terms of categories and sample size. Such groups have been recruited from different musical genres such as folk music, classical music and jazz (Benedek, Borovnjak, Neubauer, \& Kruse-Weber, 2014), heavy metal and classical music (Butkovic \& Rancic Dopudj, 2017), music student groups (MacLellan, 2011), various instrument groups (Langendörfer, 2008), but also the general workforce (Vaag et al., 2018). However, research designs rarely include reasonably large comparison groups of non- 
musicians. To find out more about what is typical for the personality of musicians, a contrasting comparison group is preferable; musicians should be compared with individuals who are not musicians, i.e. who have no self-identity as musicians and do not perform any kind of music. Thus, to strengthen existing findings and contribute to the literature, the purpose of the current study is to show differences in BFI-personality traits between musicians and nonmusicians comparing a large sample of musicians with a selected sample of non-musicians. We expect to find differences in trait profiles such as Openness, Conscientiousness and Neuroticism.

\section{PARTICIPANTS AND PROCEDURE}

\section{PARTICIPANTS}

We applied convenience sampling and all participants were voluntarily recruited on the internet from a Facebook group called Musicians. In total, 833 individuals agreed to take part in the study; 600 of them reported that they were musicians (Are you a professional musician or do you identify yourself as a musician? 1 - yes, 2 - no) and 233 were non-musicians.

To ensure that the musicians were active and creative musicians they also had to fulfil two other criteria: 1) they played their instruments or performed music daily, and 2) they had also composed music. In total, 580 of the musicians played or performed music daily and 523 had also made music. When we combined the three selection criteria, the final net sample of musicians consisted of 509 participants (women $n=128$; men $n=381$ ) with a mean age of 28.72 years $(S D=10.58)$.

Non-musicians were selected according to three criteria: 1) did not identify themselves as musicians, 2) had not composed any kind of music, and 3) had never played a musical instrument. The final sample fulfilling the selection criteria comprised 201 individuals (women $n=162$, men $n=39$ ) with a mean age of 25.12 years $(S D=7.16)$.

\section{ASSESSMENT OF PERSONALITY TRAITS}

To assess personality traits, we used the Ten-Item Personality Measure of the Big Five dimensions (TIPI) (Gosling, Rentfrow, \& Swann, 2003). The TIPI is a short instrument and consists of 10 statements that measure the five main personality traits: Extraversion, Agreeableness, Conscientiousness, Emotional Stability (Neuroticism reversed), and Openness to experience. The subjects' answers were registered on a 7-steps Likert scale (1 - disagree strongly, 7 - agree strongly). The psychometric structure and size of TIPI is comparable with the full-scale BFI (Rammstedt,
2007). The test also has adequate levels of convergence validity in self, observer, and peer reported ratings, and good test-retest reliability (Donnellan, Oswald, Baird, \& Lucas, 2006). On average the subjects required only 6-7 minutes to complete the questionnaire, an advantage with respect to panel attrition (Lynn, 2018). Thus, the TIPI is suitable for investigating personality traits in large samples.

\section{PROCEDURE}

The TIPI questionnaire was available on the Facebook page from $23^{\text {th }}$ February to $17^{\text {th }}$ March 2015. Before the final version was available on the Facebook page the questionnaire was tested out in a pilot study. The data were transformed from Google forms to Excel and then into SPSS files (SPSS Statistics version 23).

\section{STATISTICAL ANALYSES}

In addition to descriptive statistics, we first used binary logistic regression analysis to investigate whether personality traits and gender could predict the participants' self-identification as a musician. Gender ( 1 - female, 2 - male), age and the five TIPI scores were entered as predictor variables and the dependent variable was being a musician (1 - yes) or not $(2-$ no). In our second analysis, possible trait differences between musicians and non-musicians were tested using factorial multivariate analyses of variance with covariates (MANCOVA). Personality traits show normal gender and age differences (Costa, Terracciano, \& McCrae, 2001) and there were also age and gender differences (more men than women) in our sample: $F(1,709)=19.65, p<.001$ and $\chi^{2}=183.36$, $\mathrm{d} f=1, p<.001$, respectively. Therefore, gender and age were used as covariates in the MANCOVA model. The independent variable was musician (1 - yes, $2-$ no) and dependent variables were the TIPI scores for the musicians and non-musicians.

\section{ETHICS}

The study was approved by an independent project supervisor responsible for ethical evaluation of research projects at the Department of Psychology, Inland Norway University of Applied Sciences. All procedures were in accordance with the ethical principles of the Helsinki Declaration for research involving humans (World Medical Association, 2001). Participation was voluntary, the questionnaires were responded to anonymously and no information about personal identity could be revealed. The participants were also informed that they could withdraw from the project at any time. 


\section{RESULTS}

Table 1 depicts the results of the logistic regression analysis.

The results revealed that in addition to being male, elevated levels of Openness were associated with a greater likelihood of being a musician, while elevated levels of Conscientiousness and Emotional stability-Neuroticism were associated with less likelihood of being a musician. With respect to personality traits, Openness showed the strongest association. The Hosmer-Lemeshow test indicated a good fit for the regression model: $\chi^{2}=7.10, \mathrm{~d} f=8, p=.526$. Moreover, the model accounted for a substantial amount of the variance in the dependent variable: Nagelkerke $R^{2}=.48$.

Table 2 shows the mean and estimated mean personality trait scores for musicians and non-musicians.

Musicians had significantly higher scores on Openness $F(1,706)=39.48, p<.001$ compared to non-musicians (statistical power: 1.000), but lower scores on Conscientiousness $F(1,706)=13.20, p<.01$ (power: .994). There were no significant differences between the groups in Extraversion, Agreeableness or Emotional Stability-Neuroticism.

\section{DISCUSSION}

The main scientific contribution in the current study is that musicians seem to have a different personality trait profile than non-musicians. They had significantly higher scores on Openness and lower scores on Conscientiousness. There were no significant differences in Extraversion, Agreeableness or Emotional Stability-Neuroticism. The results confirm our expected outcomes for Openness and Conscientiousness, but not for Neuroticism.
Openness stands out as the most typical personality trait for musicians, and to a lesser degree Conscientiousness. The prominent role of Openness in musicians is not surprising. Performing and composing music requires all key elements in Openness (DeYoung, 2015) such as cognitive engagement and exploration, perceptual integration, creative phantasy, emotional involvement, refined sense of aesthetics, and the ability to experience aesthetic chills (McCrae, 2007). Openness is also associated with basic cognitive processes such as working memory (Zillig, Hemenover, \& Dienstbier, 2002) and implicit learning, i.e. automatic ability to detect complex sensory patterns in the environment (Kaufman et al., 2010), apparently important cognitive functions underlying any kind of musical performance, and especially when performing complex music such as classical

Table 1

Personality traits, age and gender predicting being a musician or not. Binary logistic regression analysis

\begin{tabular}{lrcc}
\hline & Wald & B & SE \\
\hline Gender & 103.82 & $-2.47^{* * *}$ & .24 \\
Age & 7.84 & $-0.04^{* *}$ & .01 \\
Extraversion & 0.05 & 0.02 & .08 \\
Agreeableness & 0.59 & 0.08 & .11 \\
Conscientiousness & 7.96 & $0.25^{* *}$ & .09 \\
Emotional stability- & 3.52 & 0.17 & .09 \\
Neuroticism & & & \\
Openness & 63.56 & $-0.99^{* * *}$ & .12 \\
\hline
\end{tabular}

Note. Dependent variable coded as musician (1), non-musician (2). Gender was coded as female (1) and male (2). Nagelkerke $R^{2}=.48$, ${ }^{*} p<.05,{ }^{* *} p<.01,{ }^{* * *} p<.001$.

Table 2

Big Five personality trait scores for musicians and non-musicians. Multivariate analysis of variance with age and gender as covariates (MANCOVA)

\begin{tabular}{|c|c|c|c|c|c|c|c|c|c|c|c|}
\hline & \multicolumn{5}{|c|}{$\begin{array}{c}\text { Musicians } \\
n=509\end{array}$} & \multicolumn{5}{|c|}{$\begin{array}{c}\text { Non-musicians } \\
n=201\end{array}$} & \multirow[t]{2}{*}{$p$} \\
\hline & $M$ & $S D$ & Estim. & $S E$ & $95 \% \mathrm{Cl}$ & M & $S D$ & Estim. & $S E$ & $95 \% \mathrm{Cl}$ & \\
\hline Extraversion & 4.73 & 1.36 & 4.74 & .06 & $4.61-4.86$ & 4.59 & 1.39 & 4.56 & .16 & $4.35-4.87$ & ns \\
\hline Agreeableness & 4.83 & 1.01 & 4.88 & .05 & $4.78-4.97$ & 4.93 & 1.09 & 4.80 & .10 & $4.64-4.95$ & ns \\
\hline Conscientiousness & 4.66 & 1.36 & 4.68 & .06 & $4.56-4.80$ & 5.15 & 1.22 & 5.10 & .10 & $4.90-5.31$ & $<.01$ \\
\hline $\begin{array}{l}\text { Emotional stability- } \\
\text { Neuroticism }\end{array}$ & 4.52 & 1.33 & 4.41 & .06 & $4.29-4.53$ & 4.34 & 1.25 & 4.62 & .10 & $4.43-4.82$ & ns \\
\hline Openness & 5.84 & 0.83 & 5.85 & .04 & $5.76-5.93$ & 5.03 & 1.03 & 5.04 & .07 & $4.90-5.17$ & $<.001$ \\
\hline
\end{tabular}

Note. Estim. - estimated marginal means, i.e. estimated trait means after controlling for gender and age, $S E-$ standard error, $95 \% \mathrm{Cl}-95 \%$ confidence intervals, ns - no significant differences. 
symphonies. Furthermore, Openness is also related to reduced latent inhibition, a neuro-cognitive process regulating the flow of stimuli entering consciousness (Peterson, Smith, \& Carson, 2002). Not surprisingly, latent inhibition is linked to artistic creativity (Carson, Peterson, \& Higgins, 2003); “wide open” perceptual and cognitive channels are probably an advantage for creative activities such as making and playing music (McManus \& Furnham, 2006). Hence, it is not surprising that high Openness is also linked to cultural activity (Schwaba, Luhmann, Denissen, Chung, \& Bleidorn, 2018) and predicts creative artistic achievements (Kaufman et al., 2016). Finally, it should also be mentioned that there is a considerable genetic contribution to Openness (Bergeman et al., 1993), which also is the case for musicality (Gingras, Honing, Peretz, Trainor, \& Fisher, 2015; PanebiancoWarrens, 2012). It is, therefore, possible that there are shared genetic contributions between Openness and musicality (Mosing \& Ullén, 2016), although the neurobiological expression of these genes in the brain seems unclear (Levitin, 2012).

The results are in agreement with previous investigations with respect to Openness and Conscientiousness. However, contrary to Butkovic and Rancic Dopudj (2017) and Vaag et al. (2018) we did not find elevated scores for musicians in Emotional stability-Neuroticism. One possible explanation could be differences in the control samples. Our sample was specifically selected with respect to no engagement in music, while the worker sample used as a control group in the study by Vaag et al. (2018) could be more heterogeneous since interest in and use of music in the general population is quite widespread (Müllensiefen, Gingras, Musil, \& Stewart, 2014). Our samples were also younger (mean age for musicians and non-musicians was 28.72 years and 25.12 years, respectively) than the musicians in the study by Vaag et al. (2018) (mean age was 43.1) and longitudinal studies show that emotional stability seems to increase in young adulthood (age 20-40) (Roberts, Walton, \& Viechtbauer, 2006). Another factor could be related to sample characteristics of the musicians. In addition to being performing musicians they were also composing music, a creative activity, and since there is a negative association between creativity and Neuroticism (Guo, Su, \& Zhang, 2017) the musicians' level of creativity could contribute to lower Neuroticism scores. Moreover, high Neuroticism scores are associated with the use of music for emotional regulation, while our sample of musicians probably experiences music in a more cognitive and intellectual way, as is reflected in their elevated scores on Openness (Chamorro-Premuzic, Gomà-i-Freixanet, Furnham, \& Muro, 2009).

Our study also showed that musicians had significantly lower scores on Conscientiousness than nonmusicians, although the mean differences were con- siderably smaller than for Openness. This finding is in agreement with both previous studies (Vaag et al., 2018) and research showing that high Conscientiousness is related to lower creativity, elevated levels of self-discipline, motivation through targeted activity, orderliness and reliability (Costa \& McCrae, 2017). It should, however, be emphasized that performing and making music also requires discipline, orderliness and motivation, so a certain level of Conscientiousness could be advantageous, but apparently not too much. High scores on Conscientiousness seem to be more suitable for occupations requiring less creativity such as practical-technical tasks, administration and data (King et al., 2017).

Finally, contrary to Sandgren (2018) and MacLellan (2011) we could not confirm elevated scores in Agreeableness and Extraversion. This fact could be linked to differences in samples of musicians. MacLellan (2011) compared choir students and orchestra students and Sandgren (2018) compared vocalists and instrumentalists, but our sample is probably more heterogeneous. Apparently, being an Extravert could be an advantage for singers, but not so much for string or woodwind players.

\section{STRENGTHS AND LIMITATIONS}

The current study examined trait differences between musicians and a contrasting comparison group of non-musicians in a relatively large sample (in total 710 individuals; 509 musicians and 201 nonmusicians). Compared to other personality factors the results showed the prominent role of Openness in musicians. In addition to the use of an especially selected control group of non-musicians, this finding strengthens the study. However, there are limitations. Although TIPI is an appropriate measure that addressed our primary research question, the findings could have been enhanced if we had further detailed information on the personality facet scales for musicians and non-musicians. For instance, in relation to Openness, it would be interesting to have more detailed knowledge of the scores of the six facets - Fantasy, Aesthetics, Feelings, Actions, Ideas, and Values (Moutafi, Furnham, \& Crump, 2006). On the other hand, the use of a time-consuming Big Five inventory such as the NEO-PI-R would probably have resulted in high panel attrition. It could also be useful to have further information about the genre of music for the musicians, their professional work and employment status and the musical instrument they played. This kind of information could potentially provide a richer understanding of different personality traits amongst musicians. Using Facebook as a recruitment tool could raise methodological problems such as biased selection, since we have no control of the representativeness of the samples 
for the two groups. However, the size of the samples could reduce this possibility. Social media have also recruitment advantages and are frequently used in empirical research in several fields (Amon, Campbell, Hawke, \& Steinbeck, 2014; Thornton et al., 2016).

Although the current study confirms previous studies on gender inequalities among musicians showing male preponderance (Vaag et al., 2018), other investigations suggest an increasing prevalence of female musicians over the last two decades, et least in popular music (Anglada-Tort, Krause, \& North, 2019). There are also gender differences in response style to music. Women seem to be more responsive than men to the emotional effects of music, even when controlling for personality traits (Chamorro-Premuzic et al., 2009). Since gender is related both to personality and to experience and use of music, future research should pay more attention to gender.

\section{CONCLUSIONS}

The current study investigated Big Five personality traits in musicians compared with non-musicians. Musicians seem to differ from non-musicians in two traits: somewhat lower scores on Conscientiousness, and considerably higher scores on Openness to experience. Thus, Openness seems to be the most typical personality trait for musicians. There were no significant differences in Extraversion, Agreeableness or Emotional Stability (Neuroticism) between the two groups. These results suggest that musicians are more creative and openminded than non-musicians.

\section{ACKNOWLEDGEMENTS}

Thanks to Dr Rose Spencer, University of East London, for valuable comments on an earlier version of this paper.

\section{RefERENCES}

Amon, K. L., Campbell, A. J., Hawke, C., \& Steinbeck, K. (2014). Facebook as a recruitment tool for adolescent health research: a systematic review. Academic Pediatrics, 14, 439-447.

Anglada-Tort, M., Krause, A. E., \& North, A. C. (2019). Popular music lyrics and musicians' gender over time: A computational approach. Psychology of Music. https://doi.org/10.1177/0305735619871602

Benedek, M., Borovnjak, B., Neubauer, A. C., \& KruseWeber, S. (2014). Creativity and personality in classical, jazz and folk musicians. Personality and Individual Differences, 63, 117-121.

Bergeman, C. S., Chlpuer, H. M., Plomin, R., Pedersen, N. L., McClearn, G. E., Nesselroade, J. R., \& ...
McCrae, R. R. (1993). Genetic and environmental effects on openness to experience, agreeableness, and conscientiousness: An adoption/twin study. Journal of Personality, 61, 159-179.

Bucher, M. A., Suzuki, T., \& Samuel, D. B. (2019). A meta-analytic review of personality traits and their associations with mental health treatment outcomes. Clinical Psychology Review, 70, 51-63.

Butkovic, A., \& Modrusan, I. (2019). Personality differences among musicians: Real differences or stereotypes? Psychology of Music. https://doi.org/ $10.1177 / 0305735619849625$

Butkovic, A., \& Rancic Dopudj, D. (2017). Personality traits and alcohol consumption of classical and heavy metal musicians. Psychology of Music, 45, 246-256.

Buttsworth, L. M., \& Smith, G. A. (1995). Personality of Australian performing musicians by gender and by instrument. Personality and Individual Differences, 18, 595-603.

Carson, S. H., Peterson, J. B., \& Higgins, D. M. (2003). Decreased latent inhibition is associated with increased creative achievement in high-functioning individuals. Journal of Personality and Social Psychology, 85, 499-506.

Chamorro-Premuzic, T., \& Furnham, A. (2007). Personality and music: Can traits explain how people use music in everyday life? British Journal of Psychology, 98, 175-185.

Chamorro-Premuzic, T., Gomà-i-Freixanet, M., Furnham, A., \& Muro, A. (2009). Personality, self-estimated intelligence, and uses of music: A Spanish replication and extension using structural equation modeling. Psychology of Aesthetics, Creativity, and the Arts, 3, 149.

Costa Jr, P., Terracciano, A., \& McCrae, R. R. (2001). Gender differences in personality traits across cultures: robust and surprising findings. Journal of Personality and Social Psychology, 81, 322-331.

Costa Jr, P. T., \& McCrae, R. R. (2017). The NEO Inventories as instruments of psychological theory. The Oxford Handbook of the Five Factor Model, 11.

DeYoung, C. G. (2015). Openness/intellect: A dimension of personality reflecting cognitive exploration. Personality Processes and Individual Differences, 4, 369-399.

Donnellan, M. B., Oswald, F. L., Baird, B. M., \& Lucas, R. E. (2006). The mini-IPIP scales: tiny-yeteffective measures of the Big Five factors of personality. Psychological Assessment, 18, 192-203.

George, J. M., \& Zhou, J. (2001). When openness to experience and conscientiousness are related to creative behavior: an interactional approach. Journal of Applied Psychology, 86, 513-524.

Gingras, B., Honing, H., Peretz, I., Trainor, L. J., \& Fisher, S. E. (2015). Defining the biological bases of individual differences in musicality. Philosophical Transactions of the Royal Society B, 370, 20140092. 
Glisky, M. L., \& Kihlstrom, J. F. (1993). Hypnotizability and facets of openness. International Journal of Clinical and Experimental Hypnosis, 41, 112-123.

Gosling, S. D., Rentfrow, P. J., \& Swann, W. B., Jr. (2003). A very brief measure of the Big Five personality domains. Journal of Research in Personality, 37, 504-528.

Guo, J., Su, Q., \& Zhang, Q. (2017). Individual creativity during the ideation phase of product innovation: An interactional perspective. Creativity and Innovation Management, 26, 31-48.

Heilman, K. M., Nadeau, S. E., \& Beversdorf, D. O. (2003). Creative innovation: possible brain mechanisms. Neurocase, 9, 369-379. https://doi.org/10. 1076/neur.9.5.369.16553

Juslin, P. N. (2003). Five facets of musical expression: A psychologist's perspective on music performance. Psychology of Music, 31, 273-302.

Karwowski, M., \& Lebuda, I. (2016). The big five, the huge two, and creative self-beliefs: A meta-analysis. Psychology of Aesthetics, Creativity, and the Arts, 10, 214.

Kaufman, S. B., DeYoung, C. G., Gray, J. R., Jiménez, L., Brown, J., \& Mackintosh, N. (2010). Implicit learning as an ability. Cognition, 116, 321-340.

Kaufman, S. B., Quilty, L. C., Grazioplene, R. G., Hirsh, J. B., Gray, J. R., Peterson, J. B., \& DeYoung, C. G. (2016). Openness to experience and intellect differentially predict creative achievement in the arts and sciences. Journal of Personality, 84, 248-258.

Kemp, A. E. (1996). The musical temperament: Psychology and personality of musicians. Oxford: Oxford University Press.

King, D. D., Ott-Holland, C. J., Ryan, A. M., Huang, J. L., Wadlington, P. L., \& Elizondo, F. (2017). Personality homogeneity in organizations and occupations: considering similarity sources. Journal of Business and Psychology, 32, 641-653.

Langendörfer, F. (2008). Personality differences among orchestra instrumental groups: Just a stereotype? Personality and Individual Differences, 44, 610-620.

Langvik, E., Bjerkeset, O., \& Vaag, J. (2019). Personality traits and the use of manual, alternative, and mental healthcare services and medication in Norwegian musicians. Personality and Individual Differences, 142, 310-315.

Levitin, D. J. (2012). What does it mean to be musical? Neuron, 73, 633-637.

López-González, M., \& Limb, C. J. (2012). Musical creativity and the brain. Paper presented at the Cerebrum: the dana forum on brain science.

Lynn, P. (2018). Tackling panel attrition. In D. L. Vannette \& J. A. Krosnick (Eds.), The Palgrave Handbook of survey research (pp. 143-153). New York: Springer.

MacLellan, C. R. (2011). Differences in Myers-Briggs personality types among high school band, or- chestra, and choir members. Journal of Research in Music Education, 59, 85-100.

McCrae, R. R. (2007). Aesthetic chills as a universal marker of openness to experience. Motivation and Emotion, 31, 5-11.

McCrae, R. R., \& Costa Jr, P. T. (1997). Personality trait structure as a human universal. American Psychologist, 52, 509-516. https://doi.org/10.1037/0003-066X. 52.5.509

McCrae, R. R., \& Costa, P. T. (2008). Empirical and theoretical status of the five-factor model of personality traits. The SAGE Handbook of Personality Theory and Assessment, 1, 273-294.

McManus, I. C., \& Furnham, A. (2006). Aesthetic activities and aesthetic attitudes: Influences of education, background and personality on interest and involvement in the arts. British Journal of Psychology, 97, 555-587.

Mosing, M. A., \& Ullén, F. (2016). Genetic influences on musical giftedness, talent, and practice. Musical Prodigies: Interpretations from Psychology, Education, Musicology, and Ethnomusicology, 156.

Moutafi, J., Furnham, A., \& Crump, J. (2006). What facets of openness and conscientiousness predict fluid intelligence score? Learning and Individual Differences, 16, 31-42.

Müllensiefen, D., Gingras, B., Musil, J., \& Stewart, L. (2014). The musicality of non-musicians: an index for assessing musical sophistication in the general population. PloS One, 9, e89642.

Palmer, C. (1997). Music performance. Annual Review of Psychology, 48, 115-138.

Panayiotou, G., Kokkinos, C. M., \& Kapsou, M. (2014). Indirect and direct associations between personality and psychological distress mediated by dispositional coping. The Journal of Psychology, 148, 549-567.

Panebianco-Warrens, C. (2012). Will my children be musical? Exploring current research on the role of genetics and the heritability of music ability: accredited article. Musicus, 40, 3-9.

Papageorgi, I., Creech, A., \& Welch, G. (2013). Perceived performance anxiety in advanced musicians specializing in different musical genres. Psychology of Music, 41, 18-41.

Peterson, J. B., Smith, K. W., \& Carson, S. (2002). Openness and extraversion are associated with reduced latent inhibition: Replication and commentary. Personality and Individual Differences, 33, 1137-1147.

Puryear, J. S., Kettler, T., \& Rinn, A. N. (2017). Relationships of personality to differential conceptions of creativity: A systematic review. Psychology of Aesthetics, Creativity, and the Arts, 11, 59-68.

Rammstedt, B. (2007). The 10-item big five inventory. European Journal of Psychological Assessment, 23, 193-201.

Roberts, B. W., Walton, K. E., \& Viechtbauer, W. (2006). Patterns of mean-level change in personality traits 
across the life course: a meta-analysis of longitudinal studies. Psychological Bulletin, 132, 1-25.

Sandgren, M. (2018). Exploring personality and musical self-perceptions among vocalists and instrumentalists at music colleges. Psychology of Music. https://doi.org/10.1177/0305735618761572

Schwaba, T., Luhmann, M., Denissen, J. J., Chung, J. M., \& Bleidorn, W. (2018). Openness to experience and culture-openness transactions across the lifespan. Journal of Personality and Social Psychology, 115, 118-136.

Shuter-Dyson, R. (2000). Profiling music students: Personality and religiosity. Psychology of Music, 28, 190-196.

Smith, M. M., Sherry, S. B., Vidovic, V., Saklofske, D. H., Stoeber, J., \& Benoit, A. (2018). Perfectionism and the five-factor model of personality: A meta-analytic review. Personality and Social Psychology Review, 23, 367-390.

Stoeber, J., \& Eismann, U. (2007). Perfectionism in young musicians: Relations with motivation, effort, achievement, and distress. Personality and Individual Differences, 43, 2182-2192.

Thornton, L., Batterham, P. J., Fassnacht, D. B., KayLambkin, F., Calear, A. L., \& Hunt, S. (2016). Recruiting for health, medical or psychosocial research using Facebook: Systematic review. Internet Interventions, 4, 72-81.

Vaag, J., Bjørngaard, J. H., \& Bjerkeset, O. (2016). Symptoms of anxiety and depression among Norwegian musicians compared to the general workforce. Psychology of Music, 44, 234-248.

Vaag, J., Sund, E. R., \& Bjerkeset, O. (2018). Five-factor personality profiles among Norwegian musicians compared to the general workforce. Musicae Scientiae, 22, 434-445.

Watson, D. (2003). To dream, perchance to remember: Individual differences in dream recall. Personality and Individual Differences, 34, 1271-1286.

World Medical Association. (2001). World Medical Association Declaration of Helsinki. Ethical principles for medical research involving human subjects. Bulletin of the World Health Organization, 79, 373.

Yöndem, S., Yöndem, Z. D., \& Per, M. (2017). Personality traits and psychological symptoms of music and art students. Journal of Education and Training Studies, 5, 53-59.

Zhao, H., \& Seibert, S. E. (2006). The big five personality dimensions and entrepreneurial status: A meta-analytical review. Journal of Applied Psychology, 91, 259-271.

Zillig, L. M. P., Hemenover, S. H., \& Dienstbier, R. A. (2002). What do we assess when we assess a Big 5 trait? A content analysis of the affective, behavioral, and cognitive processes represented in Big 5 personality inventories. Personality and Social Psychology Bulletin, 28, 847-858. 